\title{
Risk factors for prelacteal feeding in sub-Saharan Africa: a multilevel analysis of population data from twenty-two countries
}

\author{
Anselm S Berde* and Hilal Ozcebe \\ Institute of Public Health, Hacettepe University, 06100 Sihhiye, Ankara, Turkey
}

Submitted 14 October 2016: Final revision received 13 March 2017: Accepted 15 March 2017: First published online 26 April 2017

\begin{abstract}
Objective: To examine the risk factors of prelacteal feeding (PLF) among mothers in sub-Saharan Africa (SSA).

Design: We pooled data from Demographic and Health Surveys in twenty-two SSA countries. The key outcome variable was PLF. A multilevel logistic regression model was used to explore factors associated with PLF.

Setting: Demographic and Health Surveys in twenty-two SSA countries.

Subjects: Mother-baby pairs ( $n$ 95348).

Results: Prevalence of PLF in SSA was $32.2 \%$. Plain water $(22 \cdot 1 \%)$, milk other than breast milk $(5.0 \%)$ and sugar or glucose water $(4.1 \%)$ were the predominant prelacteal feeds. In the multivariable analysis, mothers who had caesarean section delivery had $2 \cdot 25$ times the odds of giving prelacteal feeds compared with mothers who had spontaneous vaginal delivery (adjusted $\mathrm{OR}=2 \cdot 25$; 95\% CI 2.06, 2.46). Other factors that were significantly associated with increased likelihood of PLF were mother's lower educational status, first birth rank, fourth or above birth rank with preceding birth interval less than or equal to 24 months, lower number of antenatal care visits, home delivery, multiple birth, male infant, as well as having an average or small sized baby at birth. Mothers aged 20-34 years were less likely to give prelacteal feeds compared with mothers aged $\leq 19$ years. Belonging to the second, middle or fourth wealth quintile was associated with lower likelihood of PLF compared with the highest quintile.

Conclusions: To achieve optimal breast-feeding, there is a need to discourage breast-feeding practices such as PLF. Breast-feeding promotion programmes should target the at-risk sub-population groups discovered in our study.
\end{abstract}

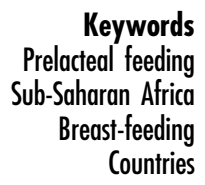

Nutrition in the early years of life plays a significant role in infant growth, development and survival, with implications for future adult health as well ${ }^{(1-3)}$. Suboptimal breast-feeding is responsible for $45 \%$ of neonatal infectious deaths, $30 \%$ of diarrhoeal deaths and $18 \%$ of acute respiratory deaths ${ }^{(4)}$ among children under 5 years of age; however, globally, only about $36 \%$ of infants less than 6 months old are exclusively breast-fed (EBF) ${ }^{(5)}$. Research has shown that optimal breast-feeding practices such as early initiation of breast-feeding and EBF are the key and easiest interventions to reduce child death and morbidity ${ }^{(6-8)}$. These interventions are particularly important in sub-Saharan Africa (SSA), where neonatal, infant and child mortality as well as malnutrition continue to be major health issues ${ }^{(9)}$.

Prelacteal feeding (PLF) is a key contributor to suboptimal breast-feeding practices because the provision of prelacteal feeds to newborns constitutes a barrier to early initiation of breast-feeding and $\mathrm{EBF}^{(10,11)}$. In addition, PLF disrupts the mother-baby dyad, causes stress in both the mother and the baby, interferes with the baby's suckling and exposes the baby to risk of infection ${ }^{(10,12-14)}$. Furthermore, prelacteal feeds have been proved to have fewer nutrients and immunological components compared with breast milk ${ }^{(15)}$.

Some studies have been carried out in SSA and other parts of the world aimed at identifying factors that influence PLF $^{(10-13,15)}$. These existing studies suggest a relationship between PLF and various background sociodemographic and maternal/child factors such as mother's age, mother's educational status, wealth quintile, sex of the child and maternal health-service utilization ${ }^{(10-13,15-17)}$. However, there is a paucity of studies identifying the determinants of PLF at the individual and country levels. Identifying predictors of PLF at various levels will play a key role when planning polices and interventions aimed at reducing PLF rates and promoting optimal breast-feeding practices such as EBF and early initiation of breast-feeding. Our study aimed to examine the risk factors of PLF among mothers in SSA, as well as explore country-level variation in PLF rates. 


\section{Methods}

\section{Data source}

We used pooled data from the Demographic and Health Survey programme in twenty-two SSA countries (Table 1). The pooled data have a hierarchical structure with individuals nested within countries. Our analysis was restricted to the last-born children born in the two years preceding the survey. The survey years in our study ranged from 2010 to 2014 and the sample size ranged from 1951 in Namibia to 11767 in Nigeria.

\section{Dependent variable}

The key outcome variable, PLF rate, was defined as giving the baby anything to drink other than breast milk in the first three days after delivery. This definition was according to the survey ${ }^{(18)}$.

\section{Explanatory variables}

We grouped individual-level explanatory variables into two categories, namely sociodemographic characteristics and clinical factors. Sociodemographic variables included the following. Mother's age at birth was grouped into $\leq 19$ years, 20-34 years and $\geq 35$ years (reference category (ref.) $=\leq 19$ years). Mother's education was classified into no education, primary, and secondary or above (ref. = secondary or above). Mother's occupation was grouped into non-working and working (ref.=non-working). Household wealth index was based on wealth quintiles, with the first (lowest) quintile being the poorest, then the second, third (middle), fourth and fifth (highest) quintile being the richest (ref. $=$ highest). Place of residence was grouped into urban and rural (ref.=urban). Birth rank and interval was categorized into: 1 st birth rank; 2nd-3rd birth rank, interval $\leq 24$ months; 2nd-3rd birth rank, interval $>24$ months; $\geq 4$ th birth rank, interval $\leq 24$ months; and $\geq 4$ th birth rank, interval $>24$ months (ref. $=\geq 4$ th birth rank, interval $>24$ months). Sex of the child was categorized into female and male (ref. = female), while size of the child at birth was grouped into average, small and large (ref.= large). The clinical explanatory variables considered in the study included: number of antenatal care (ANC) visits, categorized into $0,1-3$ and $\geq 4$ (ref. $=\geq 4$ ANC visits); place of delivery, grouped into home and health facility (ref. = health facility); mode of delivery, categorized into spontaneous vaginal delivery and caesarean section (ref.= spontaneous vaginal delivery); and birth status, grouped into single birth and multiple birth (ref. = single birth).

In addition to the individual mother/baby-level characteristics, we also included contextual country-level factors; these included total health expenditure as a percentage of gross domestic product, adult female literacy rate and proportion of women in the country who delivered at a health facility. The proportion of women with a health facility delivery was derived from relevant individual-level data, while total health expenditure and adult female literacy rate were obtained from the World Bank database ${ }^{(19)}$.

Table 1 The Demographic and Health Surveys from sub-Saharan African countries included in the present study

\begin{tabular}{|c|c|c|c|c|}
\hline Country & Survey year & $\begin{array}{l}\text { No. of last-born children } \\
\text { under } 2 \text { years of age* }\end{array}$ & $n$ & $\%$ \\
\hline Benin & 2011 & 4827 & 872 & $18 \cdot 1$ \\
\hline Burundi & 2010 & 2976 & 228 & $7 \cdot 4$ \\
\hline Côte d'Ivoire & 2011 & 2954 & 1925 & $67 \cdot 0$ \\
\hline Ethiopia & 2011 & 4148 & 1175 & $27 \cdot 2$ \\
\hline Ghana & 2014 & 2291 & 335 & $15 \cdot 1$ \\
\hline Gambia & 2013 & 3392 & 557 & $16 \cdot 9$ \\
\hline Guinea & 2012 & 2738 & 1638 & $59 \cdot 8$ \\
\hline Kenya & 2014 & 3760 & 542 & $15 \cdot 5$ \\
\hline Mozambique & 2011 & 4475 & 270 & $5 \cdot 7$ \\
\hline Nigeria & 2013 & 11767 & 7147 & 60.5 \\
\hline Niger & 2012 & 4668 & 2497 & 49.5 \\
\hline Namibia & 2013 & 1951 & 190 & $10 \cdot 3$ \\
\hline Sierra Leone & 2013 & 4449 & 971 & $21 \cdot 2$ \\
\hline Togo & 2013 & 2725 & 315 & $12 \cdot 0$ \\
\hline Zambia & 2013 & 4836 & 198 & $4 \cdot 1$ \\
\hline Zimbabwe & 2010 & 2357 & 311 & $13 \cdot 1$ \\
\hline All & & 95348 & & $32 \cdot 2 \ddagger$ \\
\hline
\end{tabular}

*Unweighted cases.

†Individual countries' sample weights, $n$ and \%.

łBased on pooled sample weights, derived from women's individual weights and population size of women aged 15-49 years in the respective countries. 
Although it would have been desirable to include other sociodemographic and clinical covariates, this was hindered by the lack of comparative data with regard to those variables. For example, some types of religious groups were predominant in some countries and almost non-existent in others.

\section{Statistical analysis}

Sample characteristics are given as unweighted case numbers and percentages, whereas overall PLF prevalence in SSA and PLF distribution by different explanatory variables are reported as weighted percentages based on women's individual weights and population size of women aged 15-49 years in the respective countries ${ }^{(20)}$. The $\chi^{2}$ test and logistic regression were performed to determine unadjusted associations of sociodemographic characteristics and clinical factors with PLF status in SSA. Due to the hierarchical structure of the data with 95348 mother-baby pairs nested within twenty-two countries, for the multivariable analysis we applied a multilevel logistic regression to explore factors associated with PLF using MLwiN multilevel software; mother-baby pairs made up the first level while countries constituted the second level. Parameter estimates using MLwiN were based on the second-order predictive (or penalized) quasi-likelihood (PQL) procedure.

The proportion of the variance in PLF due to differences between countries, the intra-country correlation coefficient, was calculated as: $\rho_{u}=\sigma_{u}^{2} /\left(\sigma_{u}^{2}+\sigma_{e}^{2}\right)$, where $\sigma_{u}^{2}$ is the total variance at country level and $\sigma_{e}^{2}$ is the total variance at the individual mother-baby pair level.

In the multilevel logistic regression models, the level one residuals, $e_{i j k}$, were assumed to follow a standard logistic distribution with mean of 0 and variance $\sigma_{e}^{2}=\pi^{2} / 3$, where $\pi=3 \cdot 1416^{(21)}$.

In the present paper we used country-level residuals to explore country-level variations in PLF by constructing simultaneous $95 \%$ CI using caterpillar plots. The width of the interval to achieve a $5 \%$ significance was set at $1 \cdot 39 \sigma^{(22)}$. Countries whose CI did not overlap were considered significant at the $5 \%$ level. The simultaneous CI were constructed before and after controlling for sociodemographic and clinical factors.

\section{Results}

\section{Study population}

Tables 2 and 3 show descriptive statistics for the pooled sample of mother-baby pairs. A larger proportion of mothers belonged to the age group of 20-34 years (69.1\%). Nearly $45 \%$ of mothers had no education and approximately $72 \%$ of mothers resided in rural areas. The highest proportion of deliveries was in health facilities $(62 \cdot 1 \%)$. Male and female children were more or less equal in the sample.

\section{Prevalence of prelacteal feeding and types of prelacteal feeds in sub-Sabaran Africa}

Table 1 shows the overall prevalence of PLF based on pooled sample weights, derived from women's individual weights and population size of women aged 15-49 years in the respective countries, as well as the prevalence of PLF in each of the twenty-two SSA countries based on individual countries' sample weights. The overall PLF prevalence in SSA was $32 \cdot 2 \%$, while PLF prevalence was noted to be highest in Côte d'Ivoire $(67 \cdot 0 \%)$ and Nigeria (60.5\%) and lowest in Zambia (4.1\%) and Malawi (2.5\%).

Table 4 shows the types of prelacteal feeds given in SSA. Overall, plain water $(22 \cdot 1 \%)$ was predominantly given in SSA, $5.0 \%$ of mothers gave milk other than breast milk while $4.1 \%$ gave sugar or glucose water. Gripe and honey were among the least administered prelacteal feeds. Table 4 also shows the distribution of the major types of prelacteal feeds in each of the twenty-two SSA countries based on individual countries' sample weights. Milk other than breast milk was predominantly given in Congo Brazzaville and Niger (both 14.4\%) and was least administered in Malawi, Liberia and Burkina Faso. On the other hand, plain water was frequently given in Côte d'Ivoire (58.8\%) and Nigeria (53.1\%) and least given in Malawi and Zambia. Sugar or glucose water was predominantly given in Niger (14.3\%) and Guinea (13.6\%); however, it was least administered in Malawi and Mozambique.

\section{Descriptive, unadjusted associations with prelacteal feeding status in sub-Sabaran Africa}

Tables 2 and 3 in addition show the associations between PLF and explanatory variables in SSA overall based on pooled sample weights, derived from women's individual weights and population size of women aged 15-49 years in the respective countries. The highest rate of PLF was observed among mothers in the following categories: age group $\leq 19$ years, no education status, working status, lowest wealth quintile, living in rural areas, having $\geq 4$ th birth rank and preceding interval $\leq 24$ months, having a male child, mother's perception of baby's size at birth to be small, not receiving ANC visits, place of delivery being home, having spontaneous vaginal delivery and multiple birth.

\section{Multivariable analysis}

Table 5 shows the adjusted associations between PLF and explanatory variables. After full adjustment (model 2), the odds of PLF was significantly lower for mothers aged 20-34 years compared with younger mothers in the age group $\leq 19$ years. Mothers with lower educational status (no education and primary educational status) were significantly more likely to give prelacteal feeds compared with mothers having secondary or above educational status. Furthermore, belonging to the second, middle or fourth household wealth quintile was associated with significantly lower likelihood of PLF compared with the 
Table 2 Characteristics of last-born children under 2 years of age and children who received a prelacteal feed, by demographic and socio-economic characteristics, in twenty-two sub-Saharan African countries, 2010 to 2014

\begin{tabular}{|c|c|c|c|c|c|c|c|}
\hline \multirow[b]{2}{*}{ Characteristic } & \multicolumn{2}{|c|}{ Total $^{\star}$} & \multicolumn{2}{|c|}{ PLF } & \multicolumn{3}{|c|}{ Crude odds* } \\
\hline & $n$ & $\%$ & $\% \dagger$ & $P$ value $\ddagger$ & OR & $95 \% \mathrm{Cl}$ & $P$ value \\
\hline \multicolumn{8}{|l|}{ Mother's age at birth (years) } \\
\hline$\leq 19$ & 14994 & $15 \cdot 7$ & $37 \cdot 3$ & \multirow[t]{3}{*}{$<0.001$} & & Ref. & Ref. \\
\hline $20-34$ & 65915 & $69 \cdot 1$ & $30 \cdot 9$ & & 0.84 & $0.81,0.88$ & $<0.001$ \\
\hline$\geq 35$ & 14439 & $15 \cdot 1$ & $33 \cdot 4$ & & 0.91 & $0.86,0.96$ & $<0.001$ \\
\hline \multicolumn{8}{|l|}{ Mother's education } \\
\hline No education & 42797 & 44.9 & $42 \cdot 5$ & \multirow[t]{3}{*}{$<0.001$} & 1.82 & $1.75,1.89$ & $<0.001$ \\
\hline Primary & 29630 & $31 \cdot 1$ & $22 \cdot 2$ & & 0.78 & $0.74,0.81$ & $<0.001$ \\
\hline Secondary or above & 22906 & $24 \cdot 0$ & $26 \cdot 2$ & & & Ref. & Ref. \\
\hline \multicolumn{8}{|l|}{ Mother's occupation } \\
\hline Non-working & 33357 & 35.4 & $32 \cdot 0$ & \multirow[t]{2}{*}{$<0.001$} & & Ref. & Ref. \\
\hline Working & 60905 & 64.6 & $32 \cdot 3$ & & 0.98 & $0.95,1.01$ & 0.126 \\
\hline \multicolumn{8}{|l|}{ Wealth index } \\
\hline Lowest & 23616 & 24.8 & 39.1 & \multirow[t]{5}{*}{$<0.001$} & 1.22 & $1 \cdot 16,1 \cdot 28$ & $<0.001$ \\
\hline Second & 20770 & 21.8 & 34.7 & & 1.13 & $1.08,1 \cdot 19$ & $<0.001$ \\
\hline Middle & 19045 & $20 \cdot 0$ & 30.4 & & 1.01 & $0.96,1.06$ & 0.691 \\
\hline Fourth & 17245 & $18 \cdot 1$ & $28 \cdot 0$ & & 0.98 & $0.93,1.04$ & 0.528 \\
\hline Highest & 14672 & 15.4 & 26.5 & & & Ref. & Ref. \\
\hline \multicolumn{8}{|l|}{ Place of residence } \\
\hline Urban & 26913 & $28 \cdot 2$ & 29.7 & \multirow[t]{2}{*}{$<0.001$} & & Ref. & Ref. \\
\hline Rural & 68435 & $71 \cdot 8$ & $33 \cdot 3$ & & 1.13 & $1.09,1.17$ & $<0.001$ \\
\hline \multicolumn{8}{|l|}{ Combined birth rank and interval } \\
\hline 1st birth rank & 19700 & $20 \cdot 7$ & $33 \cdot 5$ & \multirow[t]{5}{*}{$<0.001$} & 0.99 & $0.95,1.03$ & 0.605 \\
\hline 2nd-3rd birth rank, $\leq 24$ months & 5785 & $6 \cdot 1$ & $32 \cdot 1$ & & 0.96 & $0.90,1.02$ & 0.170 \\
\hline 2nd-3rd birth rank, >24 months & 26837 & $28 \cdot 2$ & $29 \cdot 0$ & & 0.83 & $0.80,0.86$ & $<0.001$ \\
\hline$\geq 4$ th birth rank, $\leq 24$ months & 6871 & $7 \cdot 2$ & 33.9 & & 1.07 & $1.01,1 \cdot 14$ & 0.017 \\
\hline$\geq 4$ th birth rank, $>24$ months & 35974 & $37 \cdot 8$ & 33.5 & & & Ref. & Ref. \\
\hline \multicolumn{8}{|l|}{ Sex of child } \\
\hline Male & 48248 & 50.6 & $32 \cdot 6$ & \multirow[t]{2}{*}{$<0.001$} & \multirow[t]{2}{*}{1.02} & $1.00,1.06$ & 0.106 \\
\hline Female & 47100 & 49.4 & 31.8 & & & Ref. & Ref. \\
\hline \multicolumn{8}{|l|}{ Child's size at birth } \\
\hline Large & 37236 & 39.7 & 30.5 & \multirow[t]{3}{*}{$<0.001$} & & Ref. & Ref. \\
\hline Average & 41417 & $44 \cdot 1$ & $31 \cdot 7$ & & 1.01 & $0.98,1.04$ & 0.554 \\
\hline Small & 15254 & $16 \cdot 2$ & 37.9 & & 1.33 & $1 \cdot 28,1.39$ & $<0.001$ \\
\hline
\end{tabular}

PLF, prelacteal feeding; Ref., reference category.

*Unweighted.

†Based on pooled sample weights, derived from women's individual weights and population size of women aged 15-49 years in the respective countries.

$\ddagger P$ value was based on Pearson's $x^{2}$.

Table 3 Characteristics of last-born children under 2 years of age and children who received a prelacteal feed, by clinical factors, in twenty-two sub-Saharan African countries, 2010 to 2014

\begin{tabular}{|c|c|c|c|c|c|c|c|}
\hline \multirow[b]{2}{*}{ Characteristic } & \multicolumn{2}{|c|}{ Total $^{*}$} & \multicolumn{2}{|c|}{ PLF } & \multicolumn{3}{|c|}{ Crude odds* } \\
\hline & $n$ & $\%$ & $\% \dagger$ & $P$ value $\neq$ & OR & $95 \% \mathrm{Cl}^{*}$ & $P$ value \\
\hline \multicolumn{8}{|l|}{ No. of antenatal care visits } \\
\hline 0 & 11717 & $12 \cdot 5$ & $47 \cdot 4$ & \multirow[t]{3}{*}{$<0.001$} & $2 \cdot 91$ & $2.79,3.03$ & $<0.001$ \\
\hline $1-3$ & 33286 & $35 \cdot 6$ & $27 \cdot 4$ & & 1.06 & $1.03,1.10$ & $<0.001$ \\
\hline$\geq 4$ & 48538 & 51.9 & $28 \cdot 2$ & & & Ref. & Ref. \\
\hline \multicolumn{8}{|l|}{ Place of delivery } \\
\hline Home & 35782 & 37.9 & 43.2 & \multirow[t]{2}{*}{$<0.001$} & \multirow[t]{2}{*}{2.57} & $2.49,2.65$ & $<0.001$ \\
\hline Health facility & 58627 & $62 \cdot 1$ & 21.9 & & & Ref. & Ref. \\
\hline \multicolumn{8}{|l|}{ Mode of delivery } \\
\hline Spontaneous vaginal delivery & 91196 & $95 \cdot 8$ & $32 \cdot 4$ & \multirow[t]{2}{*}{$<0.001$} & & Ref. & Ref. \\
\hline Caesarean section & 3972 & $4 \cdot 2$ & $29 \cdot 1$ & & 1.05 & $0.98,1.13$ & 0.199 \\
\hline \multicolumn{8}{|l|}{ Birth status } \\
\hline Single birth & 93644 & $98 \cdot 2$ & $32 \cdot 1$ & \multirow[t]{2}{*}{$<0.001$} & \multicolumn{2}{|r|}{ Ref. } & Ref. \\
\hline Multiple birth & 1704 & 1.8 & $39 \cdot 1$ & & $1 \cdot 18$ & $1.06,1.31$ & 0.003 \\
\hline
\end{tabular}

PLF, prelacteal feeding; Ref., reference category.

*Unweighted.

†Based on pooled sample weights, derived from women's individual weights and population size of women aged 15-49 years in the respective countries.

$\ddagger P$ value was based on Pearson's $x^{2}$. 
Table 4 Distribution of prelacteal feeds in twenty-two sub-Saharan African countries, 2010 to 2014

\begin{tabular}{|c|c|c|c|c|c|}
\hline Country & $\begin{array}{l}\text { Milk other than } \\
\text { breast milk* } \\
(\%)\end{array}$ & $\begin{array}{c}\text { Plain water* } \\
(\%)\end{array}$ & $\begin{array}{c}\text { Sugar or } \\
\text { glucose water* } \\
\text { (\%) }\end{array}$ & $\begin{array}{c}\text { Gripe* } \\
(\%)\end{array}$ & $\begin{array}{c}\text { Honey* }^{*} \\
(\%)\end{array}$ \\
\hline Burkina Faso ( $n$ 5911) & 0.8 & $29 \cdot 1$ & $4 \cdot 2$ & 0.8 & 0 \\
\hline Benin $(n$ 4810) & 1.7 & $10 \cdot 9$ & $4 \cdot 7$ & 1.9 & 0.2 \\
\hline Burundi ( $n$ 3063) & $2 \cdot 8$ & 1.4 & $2 \cdot 0$ & 0.4 & 0.2 \\
\hline Democratic Republic of the Congo ( $n$ 6987) & $1 \cdot 1$ & 4.4 & 4.8 & 0.3 & 0 \\
\hline Congo Brazzaville ( $n$ 3203) & 14.4 & $18 \cdot 6$ & 4.5 & 0.1 & - \\
\hline Côte d'Ivoire (n 2872) & 1.6 & $58 \cdot 8$ & $2 \cdot 2$ & 0.2 & $2 \cdot 2$ \\
\hline Ethiopia $(n$ 4321) & 4.7 & $5 \cdot 3$ & 3.5 & $0 \cdot 1$ & 0.1 \\
\hline Ghana ( $n$ 2225) & 1.1 & 7.4 & 0.8 & 0.4 & 0 \\
\hline Gambia (n 3298) & 1.4 & $10 \cdot 5$ & $4 \cdot 2$ & 0.1 & $2 \cdot 3$ \\
\hline Guinea ( $n$ 2739) & 3.4 & 34.8 & $13 \cdot 6$ & $2 \cdot 1$ & 0.6 \\
\hline Kenya ( $n$ 3495) & $2 \cdot 2$ & 5.9 & $4 \cdot 1$ & 0.6 & 0.1 \\
\hline Liberia ( $n$ 2586) & 0.8 & $5 \cdot 3$ & $3 \cdot 1$ & $1 \cdot 1$ & 0 \\
\hline Mali $(n$ 3856) & $2 \cdot 3$ & 10.5 & 4.0 & 1.6 & 1.7 \\
\hline Malawi (n 7535) & 0.4 & 0.5 & $0 \cdot 1$ & 0.5 & 0 \\
\hline Mozambique (n 4780) & 0.9 & 3.6 & $0 \cdot 1$ & - & 0.1 \\
\hline Nigeria $(n 11809)$ & $10 \cdot 7$ & $53 \cdot 1$ & $5 \cdot 3$ & 1.9 & $1 \cdot 7$ \\
\hline Niger ( $n$ 5047) & 14.4 & 23.0 & $14 \cdot 3$ & 0.3 & 0.8 \\
\hline Namibia ( $n$ 1854) & 4.0 & $2 \cdot 1$ & 0.4 & 0.8 & 0 \\
\hline Sierra Leone ( $n$ 4589) & $3 \cdot 8$ & $17 \cdot 5$ & 1.6 & 0.7 & 0 \\
\hline Togo (n 2619) & 1.8 & 5.9 & $3 \cdot 0$ & 0.4 & 0.4 \\
\hline Zambia (n 4818) & 1.0 & 0.9 & 1.2 & 0 & 0 \\
\hline Zimbabwe ( $n$ 2363) & 3.4 & $7 \cdot 1$ & 0.3 & 0.4 & 0 \\
\hline All $†$ & $5 \cdot 0$ & $22 \cdot 1$ & $4 \cdot 1$ & NR & NR \\
\hline
\end{tabular}

highest household wealth quintile. Mothers with 1st birth rank had $25 \%$ higher odds of giving prelacteal feeds compared with mothers with $\geq 4$ th birth rank and preceding birth interval $>24$ months. Also, compared with mothers with $\geq 4$ th birth rank and preceding birth interval $>24$ months, mothers with $\geq 4$ th birth rank and shorter preceding birth interval of $\leq 24$ months had higher odds of giving prelacteal feeds. There was a small positive association between PLF and having a male child compared with having a female child. Mothers who perceived their child as average or small were found to be more likely to give prelacteal feeds compared with mothers who perceived the size of their child at birth to be large.

Mothers with no ANC visits and mothers with 1-3 ANC visits had 34 and $11 \%$ higher odds of giving prelacteals feeds, respectively, compared with mothers who had $\geq 4$ ANC visits. With regard to place of delivery, mothers who delivered at home had higher odds of giving prelacteal feeds compared with mothers who delivered in the hospital. The study findings, in addition, revealed that mothers who delivered via caesarean section had 2.25 times the odds of giving prelacteal feeds compared with mothers who had spontaneous vaginal delivery. Furthermore, mothers with multiple births had $20 \%$ higher odds of giving prelacteal feeds compared with mothers with single births.

At the country level, higher total health expenditure as a percentage of gross domestic product was associated with lower PLF rate.

\section{Country-level variations}

The intra-country correlation was estimated to be $29 \cdot 0 \%$ in model 0 . However, after controlling for sociodemographic, clinical and contextual country-level factors (model 2), approximately $19 \cdot 0 \%$ of the total unexplained variation of PLF rates could be attributed to unobserved country-level factors. Figure 1 shows the simultaneous CI of country-level residuals in the null model (model 0). Mothers from Côte d'Ivoire, Nigeria, Guinea, Niger, Congo Brazzaville, Burkina Faso and Ethiopia had significantly higher likelihood of giving prelacteal feeds compared with mothers from Benin, Gambia, Kenya, Ghana, Togo, Zimbabwe, Namibia, Democratic Republic of the Congo, Liberia, Burundi, Mozambique, Zambia and Malawi. Figure 2 shows corresponding results from model 1, which controlled for sociodemographic factors. Mothers from Côte d'Ivoire, Nigeria, Namibia, Congo Brazzaville, Guinea and Sierra Leone had significantly higher likelihood of PLF compared with mothers from Mali, Ghana, Liberia, Democratic Republic of the Congo, Benin, Zambia, Malawi and Mozambique. As shown in Fig. 3, further adding clinical variables to the model (model 2) led to the following changes: mothers from Côte d'Ivoire, Congo Brazzaville, Namibia, Burkina Faso, Nigeria and Guinea had significantly higher likelihood of giving prelacteal feeds compared with mothers from Mali, Ghana, Democratic Republic of the Congo, Togo, Liberia, Benin, Ethiopia, Zambia, Malawi and Mozambique. 


\begin{tabular}{|c|c|c|c|c|c|c|c|c|c|}
\hline & \multicolumn{3}{|c|}{ Model 0} & \multicolumn{3}{|c|}{ Model 1} & \multicolumn{3}{|c|}{ Model 2} \\
\hline & OR & $95 \% \mathrm{Cl}$ & $P$ value & OR & $95 \% \mathrm{Cl}$ & $P$ value & OR & $95 \% \mathrm{Cl}$ & $P$ value \\
\hline $\begin{array}{l}\text { Fixed effects, constant } \\
\text { Sociodemographic characteristics }\end{array}$ & 0.22 & $0.14,0.36$ & $<0.001$ & 2.08 & $0.49,8.80$ & 0.320 & $2 \cdot 65$ & $0.47,15.4$ & 0.270 \\
\hline \multicolumn{10}{|l|}{ Mother's age at birth (years) } \\
\hline$\leq 19$ & & & & & Ref. & Ref. & & Ref. & Ref. \\
\hline $\begin{array}{l}20-34 \\
>35\end{array}$ & & & & $\begin{array}{l}0.85 \\
0.90\end{array}$ & $\begin{array}{l}0.81,0.90 \\
0.83,0.97\end{array}$ & $\begin{array}{r}<0.001 \\
0.007\end{array}$ & $\begin{array}{l}0.88 \\
0.93\end{array}$ & $\begin{array}{l}0.83,0.93 \\
0.86,1.00\end{array}$ & $\begin{array}{r}<0.001 \\
0.061\end{array}$ \\
\hline \multicolumn{10}{|l|}{ Mother's education } \\
\hline No education & & & & 1.43 & $1.35,1.51$ & $<0.001$ & 1.22 & $1.15,1.29$ & $<0.001$ \\
\hline Primary & & & & 1.17 & $1.11,1.23$ & $<0.001$ & 1.09 & $1.03,1.16$ & 0.002 \\
\hline Secondary or above & & & & & Ref. & Ref. & & Ref. & Ref. \\
\hline \multicolumn{10}{|l|}{ Mother's occupation } \\
\hline Non working & & & & & Ref. & Ref. & & Ref. & Ref. \\
\hline \multirow{2}{*}{\multicolumn{10}{|c|}{ Wealth index }} \\
\hline & & & & & & & & & \\
\hline Second & & & & 1.03 & $0.96,1.11$ & $\begin{array}{l}0.001 \\
0.399\end{array}$ & $\begin{array}{l}0.95 \\
0.91\end{array}$ & $\begin{array}{l}0.88,1.03 \\
0.85,0.98\end{array}$ & $\begin{array}{l}0.209 \\
0.014\end{array}$ \\
\hline Middle & & & & 0.94 & $0.87,1.00$ & 0.059 & 0.87 & $0.81,0.93$ & $<0.001$ \\
\hline Fourth & & & & 0.92 & $0.86,0.98$ & 0.012 & 0.90 & $0.84,0.96$ & 0.001 \\
\hline Highest & & & & & Ref. & Ref. & & Ref. & Ref. \\
\hline \multicolumn{10}{|l|}{ Place of residence } \\
\hline Urban & & & & & Ref. & Ref. & & Ref. & Ref. \\
\hline Rural & & & & 1.08 & $1.03,1.14$ & 0.003 & 1.00 & $0.95,1.05$ & 0.953 \\
\hline \multicolumn{10}{|l|}{ Combined birth rank and interval } \\
\hline 1st birth rank & & & & $1 \cdot 18$ & $1 \cdot 11,1.25$ & $<0.001$ & 1.25 & $1.17,1.33$ & $<0.001$ \\
\hline 2nd-3rd birth rank, $\leq 24$ months & & & & 1.03 & $0.95,1.11$ & 0.488 & 1.03 & $0.95,1.12$ & 0.415 \\
\hline 2nd-3rd birth rank, >24 months & & & & 0.96 & $0.92,1.01$ & 0.109 & 0.98 & $0.94,1.03$ & 0.454 \\
\hline$\geq 4$ th birth rank, $\leq 24$ months & & & & $1 \cdot 10$ & $1.03,1.18$ & 0.005 & 1.08 & $1.00,1.15$ & 0.040 \\
\hline$\geq 4$ th birth rank, $>24$ months & & & & & Ref. & Ref. & & Ref. & Ref. \\
\hline \multicolumn{10}{|l|}{ Sex of child } \\
\hline Female & & & & & Ref. & Ref. & & Ref. & Ref. \\
\hline Male & & & & 1.04 & $1.01,1.08$ & 0.015 & 1.04 & $1.00,1.08$ & 0.027 \\
\hline \multicolumn{10}{|l|}{ Child's size at birth } \\
\hline Average & & & & 1.11 & $1.06,1 \cdot 15$ & $<0.001$ & 1.09 & $1.05,1.13$ & $<0.001$ \\
\hline Small & & & & 1.37 & $1.30,1.44$ & $<0.001$ & 1.31 & $1.25,1.38$ & $<0.001$ \\
\hline Large & & & & & Ref. & Ref. & & Ref. & Ref. \\
\hline \multirow{2}{*}{\multicolumn{10}{|c|}{ Clinical factors }} \\
\hline \multicolumn{7}{|l|}{ No. of antenatal care visits } & & & \\
\hline 0 & & & & & & & 1.34 & $1.26,1.42$ & $<0.001$ \\
\hline $1-3$ & & & & & & & 1.11 & $1.06,1.16$ & $<0.001$ \\
\hline$\geq 4$ & & & & & & & & Ref. & Ref. \\
\hline \multicolumn{10}{|l|}{ Place of delivery } \\
\hline Home & & & & & & & 1.78 & $1.70,1.87$ & $<0.001$ \\
\hline Health facility & & & & & & & & Ref. & Ref. \\
\hline \multicolumn{10}{|l|}{ Mode of delivery } \\
\hline Spontaneous vaginal delivery & & & & & & & & Ref. & Ref. \\
\hline Caesarean section & & & & & & & 2.25 & $2.06,2.46$ & $<0.001$ \\
\hline \multicolumn{10}{|l|}{ Birth status } \\
\hline Single birth & & & & & & & & Ref. & Ref. \\
\hline Multiple birth & & & & & & & 1.20 & $1.05,1.38$ & 0.008 \\
\hline \multicolumn{10}{|l|}{ Contextual factors - country } \\
\hline Total health expenditure ( $\%$ of GDP) & & & & 0.80 & $0.67,0.95$ & 0.013 & 0.82 & $0.69,0.97$ & 0.023 \\
\hline Female literacy rate & & & & 0.98 & $0.96,0.99$ & 0.002 & 0.98 & $0.96,1.00$ & 0.050 \\
\hline \multicolumn{5}{|l|}{ Random effects, variance and SE } & 0.238 & & & & \\
\hline
\end{tabular}

GDP, gross domestic product; Ref., reference category. 


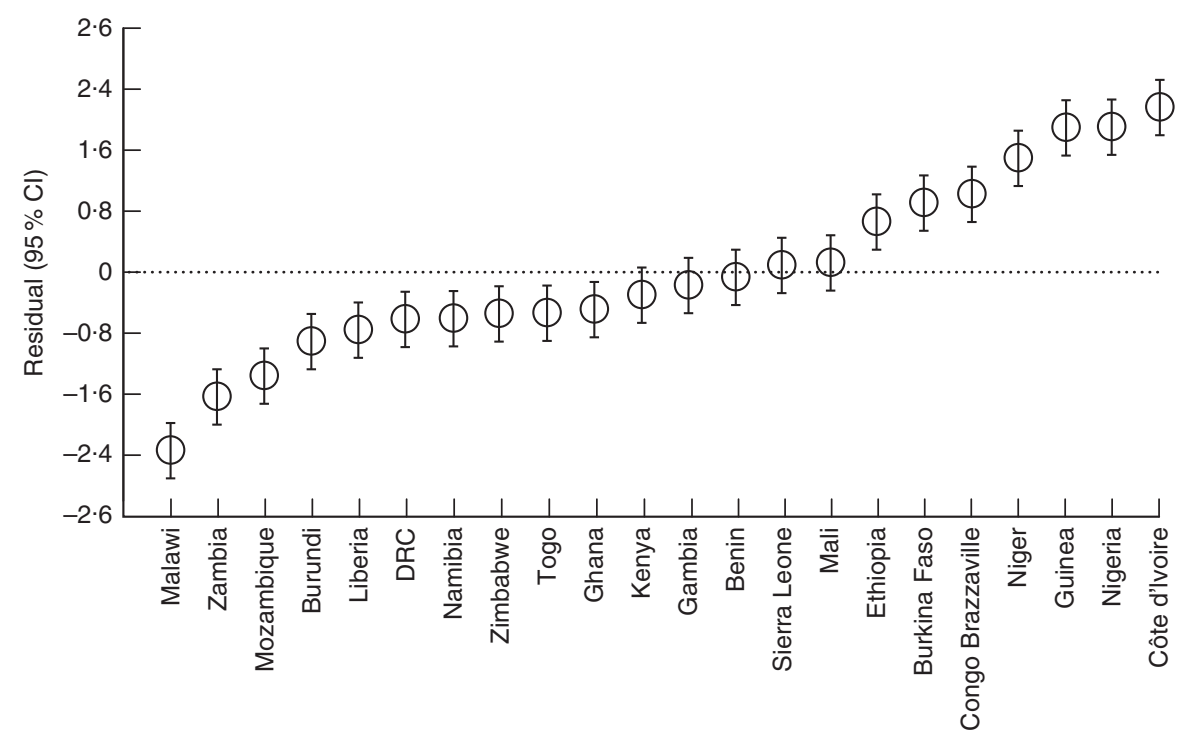

Fig. 1 Country-level variation in prelacteal feeding in twenty-two sub-Saharan African countries, 2010 to 2014: residual ( () and simultaneous $95 \% \mathrm{Cl}$ (represented by vertical bars) of country-level effects from the multivariable model with no explanatory variables, only the random country effect included (model 0; DRC, Democratic Republic of the Congo)

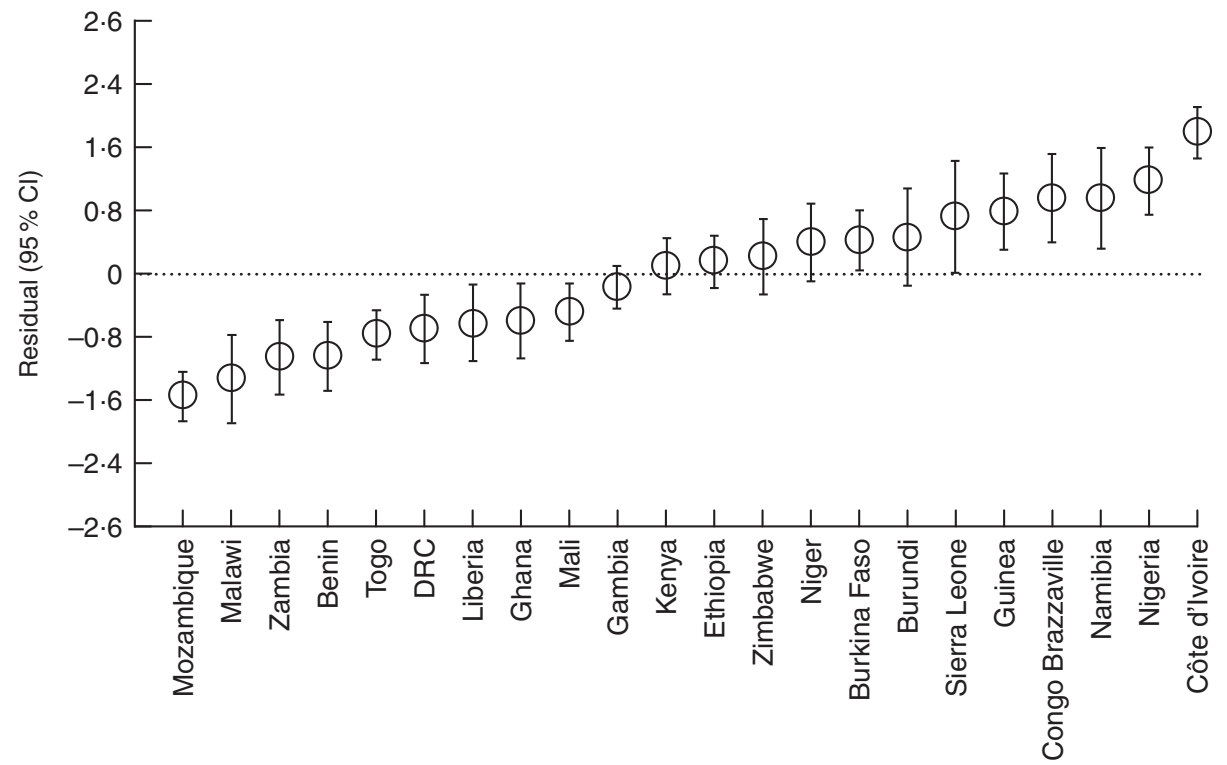

Fig. 2 Country-level variation in prelacteal feeding in twenty-two sub-Saharan African countries, 2010 to $2014:$ residual ( () and simultaneous $95 \% \mathrm{Cl}$ (represented by vertical bars) of country-level effects from the multivariable model controlling for sociodemographic characteristics (model 1; DRC, Democratic Republic of the Congo)

\section{Discussion}

The main objective of the present paper was to provide an overall view of the general pattern of PLF in SSA. We observed that in spite of the negative impact of PLF on the growth and development of children, it still remains widely practised in SSA with an overall prevalence of $32.2 \%$ in the current study. Our observed prevalence is slightly lower than the overall prevalence of PLF in seven Latin American and Caribbean countries which was reported to be $32.8 \%{ }^{(23)}$. Across countries in SSA, PLF varied from $67.0 \%$ in Côte d'Ivoire to $2.5 \%$ in Malawi. Studies done in Asian countries reported a PLF prevalence of $26.5 \%$ in $\mathrm{Nepal}^{(10)}$ and $12.3 \%$ in Timor-Leste ${ }^{(24)}$, while in Latin American countries PLF prevalence reportedly varied from $17 \cdot 6 \%$ in Guiana to $55.0 \%$ in Dominican Republic $^{(23)}$.

The commonest prelacteal feeds in SSA were plain water, milk other than breast milk and sugar or glucose water. In a previous single-country study done in Egypt, the commonest prelacteal feeds were sugar/glucose water, infant formula and herbs/decoction ${ }^{(25)}$, while honey was 


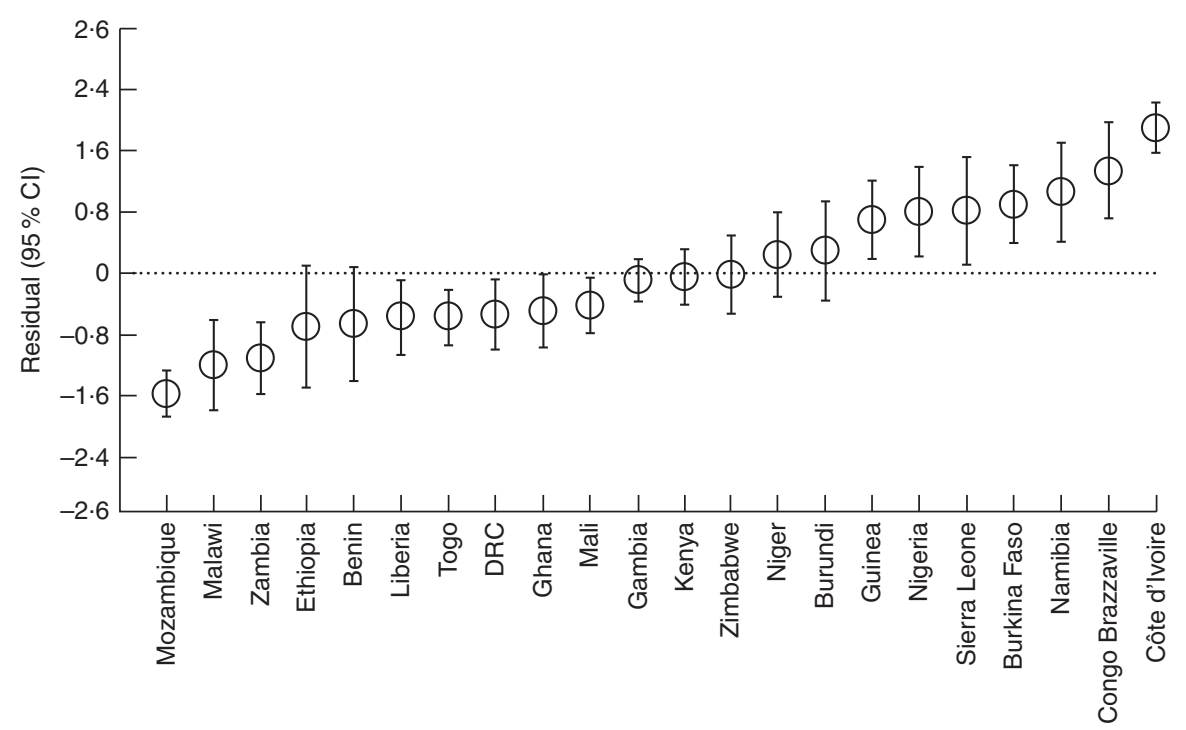

Fig. 3 Country-level variation in prelacteal feeding in twenty-two sub-Saharan African countries, 2010 to 2014: residual ( $\circ$ ) and simultaneous $95 \% \mathrm{Cl}$ (represented by vertical bars) of country-level effects from the multivariable model controlling for sociodemographic characteristics and clinical factors (model 2; DRC, Democratic Republic of the Congo)

the most administered prelacteal feed in Bangladesh ${ }^{(26)}$. Sociocultural factors such as beliefs reportedly affect breast-feeding practices according to previous studies ${ }^{(10,15,25,26)}$; thus the differences in the prevalence and types of prelacteal feeds among countries could be attributed to differences in culture and local beliefs and availability of different feeds.

The analysis presented here reveals that the significant predictors of PLF in SSA were mother's age at birth, mother's education, household wealth index, combined birth rank and interval, ANC visits, place of delivery, mode of delivery, birth status, and child's sex and size at birth; in addition, total health expenditure also affected PLF rates.

From our study, it is evident that maternal age at birth had a role in PLF rates: according to our results, mothers in the age group 20-34 years were less likely to give prelacteal feeds than mothers in the age group $\leq 19$ years. Our finding is in consonance with studies done in India ${ }^{(27)}$ and Bangladesh ${ }^{(28)}$, which also indicated that younger mothers gave more prelacteal feeds. This finding could be partly attributed to the fact that younger mothers might lack the required experience to practise appropriate infant feeding.

In agreement with a previously published study in $\mathrm{Nepal}^{(10)}$, mother's education showed an increasing risk of PLF with decreasing educational level in our study. Skafida ${ }^{(29)}$ noted that longer time spent in formal education makes mothers better equipped to educate themselves on topics such as infant nutrition and make them more aware of and prone to respond to recommendations regarding optimum breast-feeding. This could explain the low rates of PLF observed among mothers with higher educational status in the current study.

Household wealth index also emerged as a significant predictor of PLF in our study. Mothers belonging to the second, middle and fourth quintiles were less likely to give prelacteal feeds than mothers belonging to the highest quintile. Our finding is similar to other studies which showed the protective effect that lower economic status has on prelacteal feeding ${ }^{(10,16)}$. It may be theoretically possible that families belonging to the highest wealth quintile may have easy access to other expensive breastfeeding alternatives which might indirectly influence their choice of PLF ${ }^{(27)}$.

We further observed that mothers with 1 st birth rank were more likely to give prelacteal feeds than mothers with $\geq 4$ th birth rank and preceding birth interval $>24$ months. A possible explanation for this finding is that, compared with multiparas, first-time mothers have less skill and knowledge on newborn care and proper infant feeding practice ${ }^{(10)}$. The present study results in addition revealed that mothers with $\geq 4$ th birth rank and preceding birth interval $\leq 24$ months were more likely to give prelacteal feeds than mothers with $\geq 4$ th birth rank and preceding birth interval $>24$ months. This association could result from the mother's perception of being undernourished due to previous pregnancy and the short interval may influence her choice of infant feeding method; in addition, short interval between births has been reported to undermine the quality of child care vis-à-vis the child's nutrition ${ }^{(30)}$.

Consistent with the results of previous studies ${ }^{(10,11)}$, we showed increasing risk of PLF with decreased number of ANC visits. We did not find this surprising as ANC visits enable mothers to have better access and exposure to health information and educational materials regarding optimal breast-feeding.

We found delivery at home to be associated with higher odds of PLF compared with health facility delivery, which is consistent with the results of some studies conducted in 
the past ${ }^{(12,27,31)}$. Mothers who give birth in a health facility are likely to be advised by health professionals about the risks associated with $\operatorname{PLF}^{(12)}$.

There is evidence in the public health literature documenting a positive association between caesarean section and suboptimal breast-feeding ${ }^{(25,32)}$. In a study involving seven Latin American and Caribbean countries, delivery by caesarean section was associated with significantly higher odds of introducing prelacteal feeds in all countries $^{(23)}$. In consonance, we also found that caesarean section contributed to high rates of PLF, which could be explained in part by mothers' common concern that the antibiotics they receive during their care could harm their infants and the pain and discomfort associated with caesarean section ${ }^{(32-34)}$.

With regard to birth status, mothers with multiple births were more likely to give prelacteal feeds than mothers with singleton births. Yokoyama et al. ${ }^{(35)}$ and Ford et $a l .{ }^{(36)}$ reported that establishment of breast-feeding after multiple births is extremely difficult. Possible reasons could include that the mother simply does not want to breast-feed, maternal or infant illness, perception of insufficient milk supply and not enough time ${ }^{(37)}$.

We found a gender bias in terms of PLF, although some studies have indicated that the child's sex is not statistically associated with $\mathrm{PLF}^{(38,39)}$. Our study observed that mothers with a male child were more likely to give prelacteal feeds. Possible reasons for this finding could be the mothers' perception that breast milk alone might not meet the higher nutritional needs of male babies and the preference that might be given to male children in terms of care. However, this finding warrants further investigation to understand the beliefs and sociocultural factors leading to this gender difference.

The current study showed that mothers who perceived their infant to be average or small in size at birth were more likely to introduce prelacteal feeds than mothers who perceived their infants to be large. This result is in agreement with studies from Ethiopia ${ }^{(11)}$, Egypt ${ }^{(25)}$ and Timor-Leste ${ }^{(24)}$. It could be due to the misperception by mothers that their newborns of lower size birth could benefit from feeding with feeds other than breast milk and/or misperception that breast milk alone cannot meet the nutritional needs of newborns ${ }^{(11)}$.

Our study showed significant variations in PLF rates across countries in SSA. After taking into account all study covariates, $19.0 \%$ of the total unexplained variation in the risk of PLF could be attributed to unobserved country-level factors. Some other variables such as implementation level of the Baby-Friendly Hospital Initiative, maternal decision value and sociocultural variables unaccounted for in the study might have an additional effect. In addition, after controlling for all study covariates, mothers from countries like Côte d'Ivoire and Congo Brazzaville had significantly higher likelihood of giving PLF compared with mothers from countries like Malawi and Mozambique. The higher likelihood of PLF in the former countries may partly be attributed to those countries having a higher proportion of mothers in the higher-risk subgroups with respect to sociodemographic, antenatal and post-natal characteristics.

\section{Study limitations}

Our study has some limitations. First, the data set we used is cross-sectional and is subject to recall bias. Also due to the cross-sectional nature of the data, caution must be exercised in making causal influence of the identified determinants of PLF. Although we controlled for potential confounding variables, there may have been confounding by other unknown factors and known factors not included in the study such as culture and beliefs. There also may have been residual confounding from the variables we included in our multivariable analysis. For instance, residual confounding may have occurred due to difficulties in measuring socio-economic status across different settings.

\section{Conclusion}

The prevalence of PLF in SSA was observed to be high and there were differences in PLF rates among countries which is a product of the variations in availability of health facilities, demographic and socio-economic status. This constitutes a very important issue in the SSA political setting. To improve optimal breast-feeding in SSA, interventions aimed at decreasing PLF rates should target the at-risk sub-population groups discovered in our study.

\section{Acknowledgements}

Financial support: This work was supported by the Hacettepe Scientific Research Projects Coordination Unit (grant number 9862). The funder had no role in the design, analysis or writing of this article. Conflict of interest: None. Authorship: A.S.B. and H.O. planned the study; A.S.B. wrote the manuscript; H.O. made contributions to the interpretation of results and revised the manuscript; both authors read and approved the final version. Ethics of buman subject participation: The study was approved by the Ethics Committee of ICF International at Calverton, MD, USA and by the National Ethics Committee of the various countries involved in the study. Permission to use and analyse the data set was obtained by registering the study on the Demographic and Health Survey (DHS) website. Being an analysis of secondary data, the study was conducted with all participant identifiers removed.

\section{References}

1. World Health Organization (2003) The global strategy for infant and young child feeding. http://www.who.int/nutrition/ publications/infantfeeding/9241562218/en/ (accessed March 2016). 
2. World Health Organization (2008) Indicators for assessing infant and young child feeding practices. Part 1: Definitions. http://whqlibdoc.who.int/publications/2008/9789241596664_ eng.pdf (accessed March 2016).

3. UNICEF (2008) Early Childhood Development: The Key to a Full and Productive Life. New York: UNICEF.

4. World Health Organization (2009) Global Health Risks: Mortality and Burden of Disease Attributable to Selected Major Risks. Geneva: WHO.

5. World Health Organization (2016) Infant and young child feeding. http://who.int/mediacentre/factsheets/fs342/en/ (accessed June 2016).

6. Mullany LC, Katz J, Li YM et al. (2008) Breast-feeding patterns, time to initiation, and mortality risk among newborns in southern Nepal. J Nutr 138, 599-603.

7. Hajeebhoy N, Nguyen PH, Mannava P et al. (2014) Suboptimal breastfeeding practices are associated with infant illness in Vietnam. Int Breastfeed J 9, 12.

8. Edmond KM, Kirkwood BR, Amenga-Etego S et al. (2007) Effect of early infant feeding practices on infection-specific neonatal mortality: an investigation of the causal links with observational data from rural Ghana. Am J Clin Nutr 86 , 1126-1131.

9. World Health Organization, Regional Office for Africa (2015) Child health. http://www.afro.who.int/en/clustersa-programmes/frh/child-and-adolescent-health/programmecomponents/child-health.html (accessed June 2016).

10. Khanal V, Adhikari M, Sauer K et al. (2013) Factors associated with introduction of prelacteal feeding in Nepal. Findings from the Nepal Demographic and Health Survey. Int Breastfeed J 8, 9.

11. Belachew AB, Kahsay AB \& Abebe YG (2016) Individual and community-level factors associated with introduction of prelacteal feeding in Ethiopia. Arch Public Health 74, 6.

12. Legesse M, Demena M, Mesfin F et al. (2014) Prelacteal feeding practices and associated factors among mothers of children aged less than 24 months in Raya Kobo district, North Eastern Ethiopia: a cross-sectional study. Int Breastfeed J 9, 189.

13. Perez-Escamilla R, Segura-Millan S \& Canahuati J (1996) Pre-lacteal feeding is negatively associated with breastfeeding outcomes in Honduras. J Nutr 126, 2765-2773.

14. Moore ER, Anderson GC, Bergman N et al. (2012) Early skin-to-skin contact for mothers and their healthy newborn infants. Cochrane Database Syst Rev issue 5, CD003519.

15. Rogers NL, Abdi J, Moore D et al. (2011) Colostrum avoidance, prelacteal feeding and late breast-feeding initiation in rural Northern Ethiopia. Public Health Nutr 14, 2029-2036.

16. Raina SK, Vijay M \& Gurdeep S (2012) Determinants of prelacteal feeding among infants of RS Pura block of Jammu and Kashmir. J Family Med Prim Care 1, 27-29.

17. Lakati AS, Makokha OA, Binns CW et al. (2010) The effect of pre-lacteal feeding on full breastfeeding in Nairobi, Kenya. East Afr J Public Health 7, 258-262.

18. ICF Macro (2016) Demographic and Health Surveys. http:// dhsprogram.com/ (accessed November 2015).

19. The World Bank Group (2016) World Bank Open Data. http://data.worldbank.org/ (accessed November 2015).

20. United Nations (2016) 2015 Revision of World Population Prospects. http://esa.un.org/unpd/wpp/ (accessed November 2015).
21. Hedeker D \& Robert G (1996) MIXOR: a computer program for mixed effects ordinal regression analysis. Comput Methods Programs Biomed 49, 157-176.

22. Goldstein H \& Michael JRH (1995) The graphical presentation of a collection of means. J R Stat Soc Ser A Stat Soc 158, 175-177.

23. Boccolini CS, Pérez-Escamilla R, Giugliani ER et al. (2015) Inequities in milk-based prelacteal feedings in Latin America and the Caribbean: the role of cesarean section delivery. J Hum Lact 31, 89-98.

24. Khanal V, Lee AH, Nunes B et al. (2014) Prelacteal feeding of newborns in postconflict Timor-Leste. J Pediatr Gastroenterol Nutr 59, 162-166.

25. El-Gilany AH \& Abdel-Hady DM (2014) Newborn first feed and prelacteal feeds in Mansoura, Egypt. Biomed Res Int 2014, 258470.

26. Ahmed FU, Rahmani ME \& Alam MS (1996) Prelacteal feeding: influencing factors and relation to establishment of lactation. Bangladesh Med Res Counc Bull 22, 60-64.

27. Roy MP, Mohan U, Singh SK et al. (2014) Determinants of pre lacteal feeding in rural northern India. Int J Prev Med $\mathbf{5}$, 658-663.

28. Sundaram ME, Labrique AB, Mehra S et al. (2013) Early neonatal feeding is common and associated with subsequent breastfeeding behavior in rural Bangladesh. J Nutr 143, 1161-1167.

29. Skafida V (2009) The relative importance of social class and maternal education for breast-feeding initiation. Public Health Nutr 12, 2285-2292.

30. Dewey KG \& Cohen RJ (2007) Does birth spacing affect maternal or child nutritional status? A systematic literature review. Matern Child Nutr 3, 151-173.

31. Bekele Y, Mengistie B \& Mesfine F (2014) Prelacteal feeding practice and associated factors among mothers attending immunization clinic in Harari Region public health facilities, Eastern Ethiopia. Open J Prev Med 4, 529-534.

32. Nguyen PH, Keithly SC, Nguyen NT et al. (2013) Prelacteal feeding practices in Vietnam: challenges and associated factors. BMC Public Health 13, 932.

33. Duong DV, Binns CW \& Lee AH (2004) Breast-feeding initiation and exclusive breast-feeding in rural Vietnam. Public Health Nutr 7, 795-799.

34. Albokhary AA \& James JP (2014) Does cesarean section have an impact on the successful initiation of breastfeeding in Saudi Arabia? Saudi Med J 35, 1400-1403.

35. Yokoyama Y \& Ooki S (2004) Breast-feeding and bottlefeeding of twins, triplets and higher order multiple births. Nibon Koshu Eisei Zasshi 51, 969-974.

36. Ford RPK, Mitchell EA, Scragg R et al. (1994) Factors adversely associated with breastfeeding in New Zealand. J Paediatr Child Health 30, 483-489.

37. Addy HA (1975) The breast-feeding of twins. J Trop Pediatr Environ Child Health 21, 231-239.

38. Sadhasivam M \& Kanagasabapathy S (2015) Pre lacteal feeding practice among rural mothers in Tamilnadu - a questionnaire based study. Int J Biomed Adv Res 6, 484-487.

39. Nigus B, Henok K, Mussie M et al. (2016) Factors associated with prelacteal feeding in North Eastern Ethiopia: a community based cross-sectional study. Int Breastfeed J 11, 13. 